\title{
Corrosion Inhibition of Triazinedithoil for Aluminum Alloy in Hydrochloric Acid Solution
}

\author{
Fang Wang*, Ruibin Fan, Mengke Jia and Jiaolong Wang \\ College of Science, Northwest A\&F University, Xinong Road No.22, Yangling, Shaanxi 712100, China
}

\begin{abstract}
The corrosion inhibition property of 6-diallylamino-1,3,5-triazine-2,4-dithiol monosodium (DAN) for aluminum alloy corrosion in hydrochloric acid solution was investigated by weight loss, potentiodynamic polarization, cyclic voltammetry and scanning electron microscopy (SEM). The effect of DAN concentration, temperature, immersion time and acidic concentration and was studied. It was found that DAN presented excellent corrosion inhibition performance for aluminum alloy. Polarization curves revealed that DAN acted as the cathodic inhibitor. The inhibition efficiency was improved with the concentration of DAN inhibitor, while decreased with the improvement of corrosion temperature and immersion time. The adsorption isotherm of DAN inhibitor on aluminum alloy surface conformed to langmuir adsorption model and the value of $\Delta \mathrm{G} \theta$ inferred the interaction of DAN inhibitor with aluminum as chemical adsorption at $40^{\circ} \mathrm{C}$.
\end{abstract}

Keywords: Aluminum Alloy; Weight Loss; Potentiodynamic Polarization; Adsorption Isotherm; Inhibitor

\section{Introduction}

Aluminum alloy is extensively used in many engineering applications, such as automobile, aviation, house holding appliance, container and electronic device due to its excellent properties including low cost, light weight, good appearance, mechanical strength, high thermal and electrical conductivity [1]. The thin, adherent and compact oxide film formed on aluminum surface can protect the metal in various environments [2-5]. But the oxide film is amphiprotic and the metal dissolves readily in acidic or basic solutions [6]. Mineral acid, mainly hydrochloric acid is widely used to remove oxide in several industrial processes such as acid pickling, acid cleaning and oil well acidizing. Acids enhance the rate of metal dissolution and are indirectly responsible for the failure of the material. Adding a corrosion inhibitor is an important and effective method to decrease the rate of the metal dissolution in such solutions. Many organic compounds such as aliphatic and aromatic amines as well as nitrogen heterocyclic molecules can serve as corrosion inhibitor effectively [2,6-10].

Some triazine derivatives used to inhibit the corrosion of mild steel were reported previously $[11,12]$, whereas the study on triazine inhibitor for aluminum alloy was nearly mentioned. In this work, a new triazine derivative, 6-diallylamino-1,3,5-triazine-2,4-dithiol monosodium (DAN) was used to study the corrosion inhibition for aluminum alloy. According to the previous researches about DAN and its structural features $[13,14]$, it can be inferred that DAN could be an efficient inhibitor due to its special properties such as the presence of hetero atoms ( $\mathrm{N}$ and $\mathrm{S}$ ), $\mathrm{N}$-containing heterocyclic conjugate system, high solubility and low toxicity. The corrosion inhibitive ability of DAN was evaluated by weight loss, potentiodynamic polarization, cyclic voltammograms and scanning electron microscope (SEM) technique.

\section{Experimental}

\section{Materials}

The substrate for this study was AA5052 aluminum alloy with the dimension of $30 \mathrm{~mm} \times 50 \mathrm{~mm} \times 0.3 \mathrm{~mm}$ and the chemical compositions of AA5052 are shown in Table 1. The specimen was used for weight loss and the specimens with an exposed area of $1 \mathrm{~cm}^{2}$ (rest is covered by polyimide tape) were used for potentiodynamic polarization. All specimens were ultrasonically degreased with acetone for $15 \mathrm{~min}$. The deoxidation treatment was carried out in alkaline solution at $60^{\circ} \mathrm{C}$ for $1 \mathrm{~min}$, washed thoroughly with distilled water and dried at room temperature. The corrosive media $0.2 \mathrm{M} \mathrm{HCl}$ solution was prepared using $\mathrm{AR}$ grade $\mathrm{HCl}$ and double distilled water. 6-diallylamino-1,3,5triazine-2,4-dithiol monosodium (DAN) was synthesized by the reaction between 6-N,N-diallylamino-1,3,5-triazine-2,4-dichloride and $\mathrm{NaSH}$. The molecular structure of DAN is shown in Figure 1.

\section{Methods}

Weight loss measurements: Weight loss measurements were performed by immersing the aluminum alloy specimen in the glass beaker containing $\mathrm{HCl}$ solution without and with different concentration of DAN inhibitor $(0.1 \sim 2.0 \mathrm{mM})$. After the stipulated immersion time, the specimen was taken out and washed with distilled water, dried and weighed accurately using digital balance (accuracy: $\pm 0.1 \mathrm{mg}$ ). Each measurement was repeated three times and an average value was calculated. Immersion experiments were carried out at temperature of $30,40,50,60$ and $70^{\circ} \mathrm{C}$ in a digital temperature controlled water bath. The immersion time of $1,5,10,24$ and $48 \mathrm{~h}$ was controlled respectively. The corrosion inhibition efficiency $\eta \mathrm{w}(\%)$ and surface coverage $(\theta)$ can be obtained by the following equations.

$$
\begin{aligned}
& \eta_{w}(\%)=\frac{W_{0}-W_{i}}{W_{0}} \times 100 \\
& \theta=\frac{W_{0}-W_{i}}{W_{0}}
\end{aligned}
$$

*Corresponding author: Wang F, College of Science, Northwest A\&F University, Xinong Road No.22, Yangling, Shaanxi 712100, China, Tel: +86-29-87092226; E-mail: wangfang4070@nwsuaf.edu.cn

Received November 14, 2014; Accepted December 12, 2014; Published December 15, 2014

Citation: Wang F, Fan R, Jia M, Wang J (2014) Corrosion Inhibition of Triazinedithoil for Aluminum Alloy in Hydrochloric Acid Solution. J Material Sci Eng 4: 148. doi:10.4172/2169-0022.1000148

Copyright: ( 2014 Wang F, et al. This is an open-access article distributed unde the terms of the Creative Commons Attribution License, which permits unrestricted use, distribution, and reproduction in any medium, provided the original author and source are credited. 
<smiles>C=CCN(CC=C)c1nc(S)nc([As])n1</smiles>

Figure 1: The molecular structure of DAN.

Where W0 and Wi are the weight losses of AA5052 in the absence and in the presence of DAN inhibitor, respectively. And the same experiment was carried out for three times. The data in this study was an average value from three repetitions.

Electrochemical measurements: The potentiodynamic polarization and cyclic voltammogram measurements were carried out in CHI 660C electrochemical work station in a three-electrode cell system with a saturated calomel electrode (SCE) as reference electrode at $30^{\circ} \mathrm{C}$. The counter electrode was rectangular graphite in potentiodynamic polarizations study, while it was stainless steel in cyclic voltammogram study. The working electrode was pretreated AA5052. An immersion time of $1 \mathrm{~h}$ was given to allow the stabilization of the open circuit potential prior to any electrochemical measurements. The experimental solutions were $0.5 \mathrm{M} \mathrm{NaCl}$ and $0.1 \%$ $\mathrm{H} 2 \mathrm{SO} 4$, respectively. The corrosion inhibition efficiency $\eta p$ (\%) was calculated from the measured corrosion current density (Icorr) by the following relationship.

$$
\eta_{p}(\%)=\frac{\text { Iocorr }- \text { Iicorr }}{\text { Iocorr }} \times 100
$$

where Iocorr and Iicorr are the corrosion current densities of AA5052 in the absence and in the presence of DAN inhibitor, respectively.

Scanning electron microscopy (SEM): The surface morphologies of AA5052 before and after the $0.2 \mathrm{M} \mathrm{HCl}$ immersion for $24 \mathrm{~h}$ in the absence and in the presence of 2.0 M DAN inhibitor were observed by SEM (JSM-6360LV) at accelerating voltage of $20 \mathrm{kV}$.

\section{Results and Discussion}

\section{Weight loss studies}

Effect of DAN inhibitor concentration: The variation of $\eta w(\%)$ with the concentration of DAN inhibitors $(0.1 \sim 2.0 \mathrm{mM})$ for $24 \mathrm{~h}$ of immersion time in $0.2 \mathrm{M} \mathrm{HCl}$ solution at $30^{\circ} \mathrm{C}$ is presented in Figure 2. It can be seen from the figure that the corrosion inhibition efficiency is proportional to the DAN concentration up to $0.5 \mathrm{mM}$. Thereafter, a marginal increase is noticed in the range $0.5 \sim 2.0 \mathrm{mM}$ concentration. The result indicated that DAN inhibitor molecules could adsorb on the surface of aluminum alloy to form a relative complete protective layer even in low concentration. The maximal inhibition efficiency was obtained at the $2.0 \mathrm{M}$ DAN concentration. It was proposed that the adsorption rate of DAN inhibitor molecule on AA5052 surface was equal to desorption rate at the concentration.

Effect of temperature: To examine the action of inhibitors at elevated temperatures, weight loss experiments were carried out at different temperatures keeping immersion time at for $24 \mathrm{~h}$ in $0.2 \mathrm{M} \mathrm{HCl}$ solution with $2.0 \mathrm{mM}$ DAN. The variation of $\eta \mathrm{w}(\%)$ with temperature is shown in Figure 3, which indicated that $\eta w$ (\%) exhibited decrease with the increasing of experimental temperature. It is well known that decrease in efficiency with the increase of temperature is attributed to the physical adsorption. The time gap between the process of adsorption and desorption of inhibitor molecules over the metal surface is becoming shorter with increase in the temperature. Hence, the metal surface with the incomplete protective layer remains exposed to the acid environment for longer period, therefore the inhibition efficiency falls at elevated temperature [15].

Effect of immersion time: To see the effect of immersion time on $\eta w(\%)$, weight loss measurements were carried out for different immersion times, from 1 to $48 \mathrm{~h}$. The variation of $\eta \mathrm{w}$ (\%) with immersion time is shown in Figure 4. It was noted that the variation of $\eta w(\%)$ with immersion time became large significantly within the first 5 hours. When the immersion time was 5 hours, the inhibition efficiency of DAN molecules reached the highest value of $93.82 \%$. In general, the adsorption of the inhibitor molecule is often a displacement reaction involving removal of adsorbed water molecules from the metal surface. It was assumed that the adsorption rate of DAN inhibitor molecules was higher than desorption rate within 5 hours and adsorption layer existed on the metal surface to make the anti-corrosion performance improved. When the immersion time was 5 hours, the adsorption of DAN inhibitor molecules became saturated. In hydrochloric acid medium, the metal surface is negatively charged due to the specifically adsorbed $\mathrm{Cl}$ - ions on the metal surface. The nitrogen atom of the

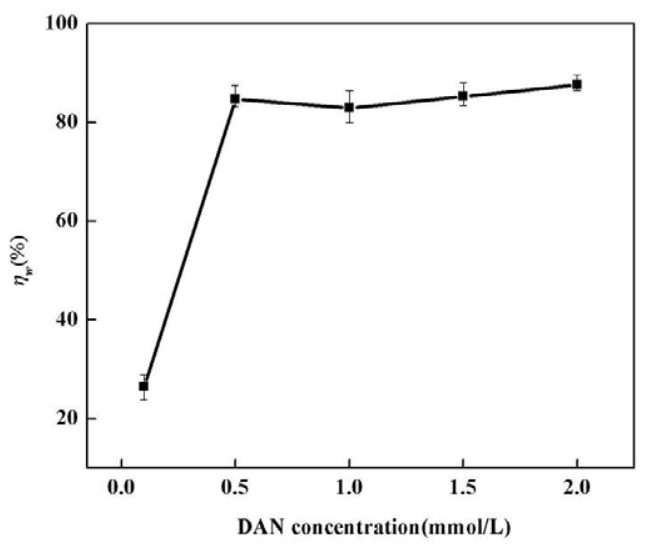

Figure 2: Variation of $\eta_{w}(\%)$ with concentration of DAN inhibitor for an immersion time $24 \mathrm{~h}$ in $0.2 \mathrm{M} \mathrm{HCl}$ solution at $30^{\circ} \mathrm{C}$

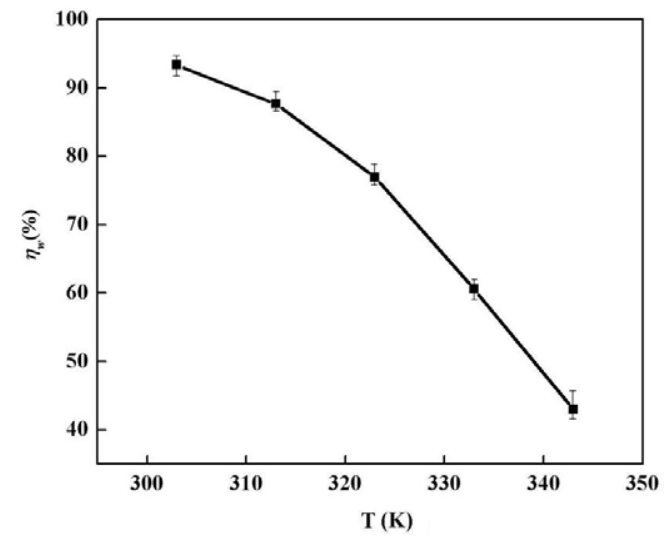

Figure 3: Variation of $\eta_{w}(\%)$ with temperature for an immersion time of $24 \mathrm{~h}$ in $0.2 \mathrm{M} \mathrm{HCl}$ solution at different temperatures. (DAN concentration is $2.0 \mathrm{M}$ ). 


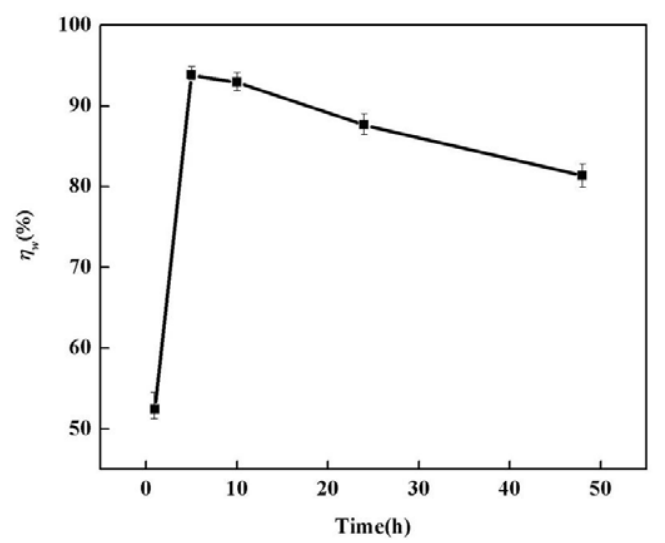

Figure 4: Variation of $\eta_{w}(\%)$ with immersion time at $30^{\circ} \mathrm{C}$ with $2.0 \mathrm{mM}$ DAN.

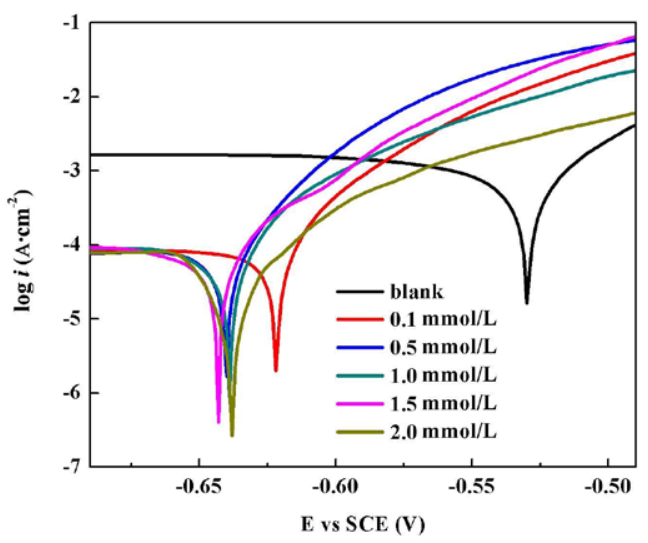

Figure 5: Tafel plots for AA5052 in $0.5 \mathrm{M} \mathrm{NaCl}$ solution containing different concentration of DAN inhibitor.

triazine ring of the DAN inhibitor can be protonated easily, due to high electron density on it, leading to positively charged inhibitor species. The adsorption can occur via electrostatic interaction between positively charged inhibitor molecules and negatively charged metal surface. Further, coordinate bond may be formed between unshared e- pairs of unprotonated nitrogen atom of the DAN inhibitor and metal surface. Additionally inhibitor molecule may be chemically adsorbed due to interaction of $\pi$ electrons of the inhibitor with metal surface. With the prolonging of immersion time, the inhibition efficiency decreased slightly, which was due to that the protective inhibitor molecules were incomplete and disorder to induce local corrosion. According to Ahamad et al. [16], the decrease of $\eta w$ (\%) with immersion time is due to increased desorption and decreased adsorption.

\section{Electrochemical studies}

Potentiodynamic polarization: Potentiodynamic polarization profiles for AA5052 in $0.5 \mathrm{M} \mathrm{NaCl}$ solution in the presence of different concentrations of DAN are presented in Figure 5. The corrosion parameters such as corrosion potential (Ecorr), corrosion current density (Icorr) and cathodic Tafel slope $(\beta c)$ can be obtained from Figure 5 as shown in Table 2 . The percentage inhibition efficiency $\eta p$ (\%) was calculated from equation (3). It could be seen that the presence of DAN inhibitor caused a prominent decrease of corrosion current densities (Icorr) and Icorr decreased with the increasing of DAN inhibitor concentration. When the adding amount of DAN inhibitor was $2.0 \mathrm{mM}$, the Icorr was the lowest with the value of $104 \mu \mathrm{A} \bullet \mathrm{cm}^{-2}$ and inhibition efficiency reached $94 \%$. From Table 1, the value of Ecorr was shifted towards negative (noble) direction with the increasing of DAN inhibitor concentration while Icorr was shifted towards lower currentdensity region, which indicated that the cathode reaction of aluminum alloy was suppressed to some extent. Therefore, the entire corrosion process was retarded in the system with DAN inhibitor molecules. In literature, it has been reported that a compound can be classified as an anodic or cathodic-type inhibitor when the change in Ecorr is greater than $85 \mathrm{mV}$ [17] with reference to blank specimen, otherwise inhibitor is treated as mixed type. In our study, maximum displacement in Ecorr value was around $113 \mathrm{mV}$, which indicated that DAN molecule mainly acted as the cathodic inhibitor [18]. The $\eta p(\%)$ values increased with increase in the inhibitor concentration and are in agreement with $\eta w$ (\%) obtained from weight loss measurements.

Cyclic voltammogram: The cyclic voltammograms curves can be used to study the surface coverage of inhibitor molecules. Figure 6 shows the cyclic voltammograms of aluminum alloy electrode in $0.1 \% \mathrm{H}_{2} \mathrm{SO}_{4}$ solution. With the scanning potential ranged from $-1.0 \mathrm{~V}$ to $2.0 \mathrm{~V}$, the current density of the blank aluminum changed significantly from 0 to $0.88 \mathrm{Acm}^{-2}$, which indicated that the surface stability of the blank was poor and apt to be corroded. Compared with the blank, the aluminum alloy electrodes in the presence of DAN inhibitor had relative lower current densities and the current density became smaller gradually with the increasing of DAN concentration. This might be attributed to the adsorption of DAN molecules on aluminum alloy surface to form the protective layer. Hence, it could block corrosive electrolyte particle through the surface of aluminum electrodes and played a protective role for metal material. Table 3 presents the mathematics area and $\eta_{\mathrm{c}}$ (\%) of cyclic voltammogram in the absence and presence of different concentrations of DAN. As the adding amount of DAN inhibitor was improved, the mathematics area of cyclic voltammogram curve reduced from 0.08653 to 0.00366 and the $\eta_{c}(\%)$ reached $96 \%$ at $2 \mathrm{mM}$ DAN concentration, which was consisted with the results of weight loss test and potentiodynamic polarization.

\begin{tabular}{|c|c|c|c|c|c|c|c|}
\hline $\mathrm{Cu}$ & $\mathrm{Si}$ & $\mathrm{Fe}$ & $\mathrm{Mn}$ & $\mathrm{Mg}$ & $\mathrm{Zn}$ & $\mathrm{Cr}$ & other \\
\hline 0.1 & 0.2 & 0.4 & 0.1 & 2.8 & 0.1 & 0.3 & 0.15 \\
\hline
\end{tabular}

Table 1: Chemical composition for aluminum alloy AA5052 (\%).

\begin{tabular}{|c|c|c|c|c|}
\hline $\boldsymbol{C} /(\mathbf{m M})$ & $\boldsymbol{E}_{\text {corr }} / \mathbf{m V} \mathbf{( v s}$ SCE) & $\boldsymbol{I}_{\text {corr }} /\left(\boldsymbol{\mu A} \cdot \mathbf{c m}^{-2}\right)$ & $\boldsymbol{\beta}_{\mathrm{c}} /(\mathbf{1} / \mathbf{V})$ & $\boldsymbol{\eta}_{\mathrm{p}} / \%$ \\
\hline 0 & -530 & 1640 & 0.934 & - \\
\hline 0.1 & -622 & 290 & 0.568 & 82 \\
\hline 0.5 & -640 & 264 & 0.857 & 84 \\
\hline 1.0 & -639 & 243 & 0.888 & 85 \\
\hline 1.5 & -643 & 176 & 0.915 & 89 \\
\hline 2.0 & -638 & 104 & 0.912 & 94 \\
\hline
\end{tabular}

Table 2: Tafel polarization parameters of the corrosion for aluminum alloy in 0.5 $\mathrm{mol} / \mathrm{L} \mathrm{NaCl}$ in the absence and presence of different concentrations of DAN.

\begin{tabular}{|c|c|c|}
\hline $\mathbf{C l}(\mathbf{m M})$ & mathematics area/(×10-4) & $\boldsymbol{\eta}_{\mathrm{c}} \mathbf{l} \%$ \\
\hline 0 & 865.3 & - \\
\hline 0.1 & 323.9 & 63 \\
\hline 0.5 & 279.7 & 68 \\
\hline 1.0 & 151.6 & 83 \\
\hline 1.5 & 97.5 & 89 \\
\hline 2.0 & 36.6 & 96 \\
\hline
\end{tabular}

Table 3: Cyclic voltammogram of the corrosion for aluminum alloy in $0.1 \% \mathrm{H}_{2} \mathrm{SO}_{4}$ in the absence and presence of different concentrations of DAN. 


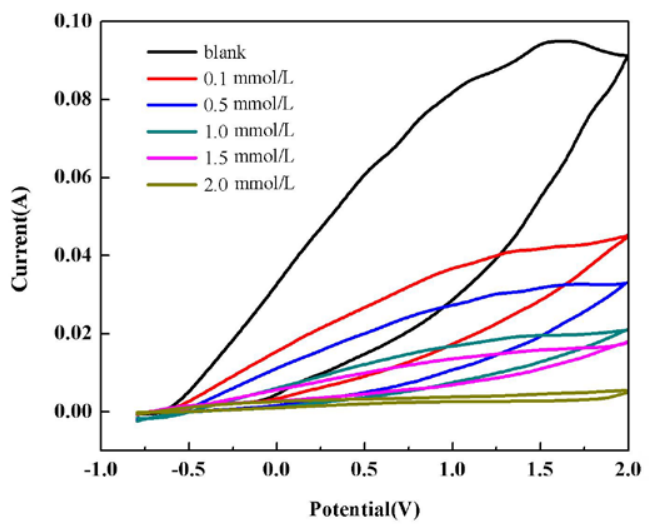

Figure 6: Cyclic voltammograms on aluminum alloy electrode in $0.1 \% \mathrm{H}_{2} \mathrm{SO}_{4}$ solution containing different concentration of DAN inhibitor. (The sweep rate is $10 \mathrm{mV} / \mathrm{s}$.)
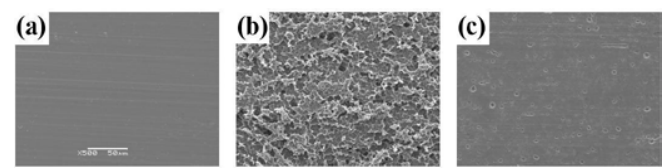

Figure 7: Surface morphology of aluminum alloy AA5052. (a) AA5052 surface before immersion; (b) AA5052 surface after $24 \mathrm{~h}$ immersion in $0.2 \mathrm{M}$ corrosive $\mathrm{HCl}$ without DAN; (c) AA5052 surface after $24 \mathrm{~h}$ immersion in 0.2 $\mathrm{M}$ corrosive $\mathrm{HCl}$ and in presence of $2.0 \mathrm{mM}$ DAN inhibitor.

\section{Scanning electron microscopy (SEM)}

The morphologies of the aluminum alloy surface were also observed before and after $24 \mathrm{~h}$ immersion in $0.2 \mathrm{M} \mathrm{HCl}$ and in absence or presence of DAN inhibitor, shown in Figure 7. It can be seen that the aluminum sheet before immersion seems smooth and the scratches, kinks and folds introduced by rolling process on AA5052 surface (Figure 7a). The AA5052 surface was severely infected by the presence of corrosive $\mathrm{HCl}$ solution as seen in Figure $7 \mathrm{~b}$. The cracks and grooves together with huge amount of irregular deep voids distributed along the surface, confirmed the role of $\mathrm{HCl}$ to make corrosion in three dimensions. Figure $7 \mathrm{c}$ showed the aluminum surface in presence of DAN inhibitor and corrosive $\mathrm{HCl}$ solution. Deep and large voids observed in Figure $7 \mathrm{~b}$ drastically reduced due to the adsorptive layers of inhibitor that prevented $\mathrm{HCl}$ penetration into the aluminum surface, which further confirmed the inhibition ability of DAN. Conclusively, the regular distribution of the DAN molecules generated the formation of consistent protective layers on AA5052 surface that could protect the metal from corrosive $\mathrm{HCl}$.

\section{Adsorption isotherm}

The inhibition efficiency of DAN molecule mainly depends on its adsorption ability at metal-solution interface. The surface coverage ( $\theta$ ) for different DAN concentrations is defined as $\eta_{w} / 100$ and can be obtained from weight loss measurements. Basic information about the interaction between inhibitor and AA5052 can be provided by the adsorption isotherm. Several adsorption isotherms like Temkin, Freundlich, Langmuir and Flory-Huggins were tested for the description of adsorption behavior of DAN molecules. Among them, the best fit was Langmuir isotherm as shown in Figure 8. It was noted that the linear correlation coefficient $(\mathrm{R}=0.99417)$ of $c / \theta$ and $c$ was very close to 1 and the slope of the straight line (1.04076) was also close to 1 , which indicated that the adsorption of DAN molecule on aluminum alloy surface obeyed Langmuir model at $40^{\circ} \mathrm{C}$. Namely, the characteristic of Langmuir adsorption isotherm is given by following equation $[19,20]$ :

$$
\frac{c}{\theta}=\frac{1}{K_{a d s}}+c
$$

where $c$ is the concentration of inhibitor, $K_{a d s}$ is the adsorptive equilibrium constant and $\theta$ is the surface coverage equal to inhibition efficiency $\eta_{w} / 100$. The $K_{a d s}$ can be calculated as $5.50 \mathrm{~L} / \mathrm{mmol}$ from the intercept of fitting formula in Figure 8. For Langmuir model, the relationship of $K_{a d s}$ and standard adsorption free energy $\left(\Delta G^{\theta}\right)$ can be expressed by the following Eq. (5).

$$
K=\frac{1}{c_{\text {solvent }}} \exp \left(\frac{-\Delta G^{\theta}}{R T}\right)
$$

where $\mathrm{R}$ is molar gas constant, $\mathrm{T}$ is temperature in Kelvin and $c_{\text {solvent }}$ is the water concentration in solution. It should be noted that the unit of $c_{\text {solvent }}$ lies in that of $K$. As can be seen from Figure 8, the unit of $K$ is $\mathrm{L} / \mathrm{mmol}$ which implies that the unit of $c_{\text {solvent }}$ is $\mathrm{mmol} / \mathrm{L}$ with the value of approximate $5.55 \times 10^{4} \mathrm{mmol} / \mathrm{L}$. Hence, the value of $\Delta G^{\theta}$ was calculated to be $-44.664 \mathrm{~kJ} / \mathrm{mol}$. The negative value of $\Delta G^{\theta}$ suggests that inhibitor molecules are spontaneously adsorbed on metal surface. The adsorption strength is directly proportional to value of $\Delta G^{\theta}$.

In general, $\Delta G^{\theta}$ value of $-20 \mathrm{~kJ} / \mathrm{mol}$ or lower indicates physisorption interaction while those around $-40 \mathrm{~kJ} / \mathrm{mol}$ or higher is generally accepted to form a coordinate bond by the charge sharing or transferring between the inhibitor molecules and the metal surface [21]. In this study, the value of $\Delta G^{\theta}\left(40^{\circ} \mathrm{C}\right)$ is $-44.664 \mathrm{~kJ} / \mathrm{mol}$. It was suggested that the chemical adsorption of DAN was most possible. It can be attributed to the presence of hetero atoms ( $\mathrm{N}$ and $\mathrm{S}$ ) and $\mathrm{N}$-containing heterocyclic conjugate system. Thus, the possible reaction centres are unshared electron pairs on hetero atoms and $\pi$ electrons of c N-containing heterocyclic conjugate system. Especially, the existence of -SH group and $-\mathrm{S}$ - in DAN molecule is in favor of chemisorb on the metal surface in acidic media [22].

\section{Conclusions}

The organic triazine compound of DAN was successfully applied as corrosion inhibitor for the aluminum alloy in $\mathrm{HCl}$ solution. DAN inhibitor formed the protective layer on aluminum surface to block the corrosion reaction and acted as a cathodic-type inhibitor. All of the experimental methods indicated that the inhibition efficiency

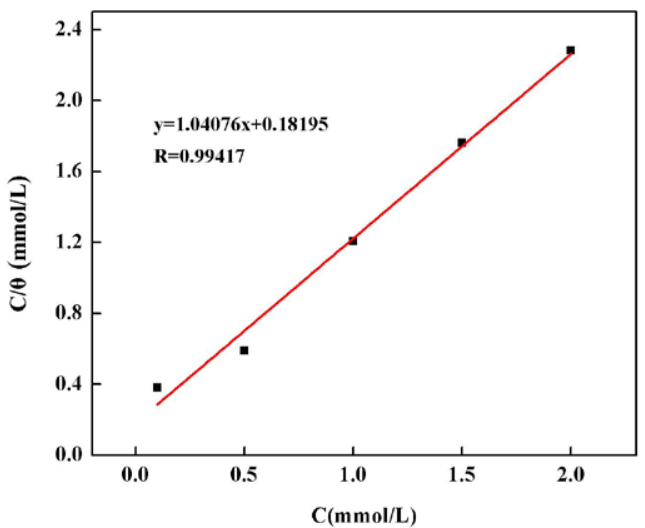

Figure 8: Langmuir isotherm adsorption isotherm of DAN in $0.2 \mathrm{M} \mathrm{HCl}$ solution. 
Citation: Wang F, Fan R, Jia M, Wang J (2014) Corrosion Inhibition of Triazinedithoil for Aluminum Alloy in Hydrochloric Acid Solution. J Material Sci Eng 4: 148. doi:10.4172/2169-0022.1000148

Page 5 of 5

was highest and more than $90 \%$ at the concentration of $2.0 \mathrm{mM}$ DAN. The adsorption of DAN molecules on aluminum alloy surface obeyed Langmuir adsorption isotherm. The $\Delta G^{\theta}$ value inferred that the adsorption process of DAN inhibitor was spontaneous and the interaction of inhibitor with aluminum alloy was chemical sorption at $40^{\circ} \mathrm{C}$. The results of weight loss, electrochemical evaluation and SEM are in good agreement.

\section{Acknowledgement}

The authors gratefully acknowledge the Fundamental Research Funds for the Central Universities (No. QN2013085) and the National Natural Science Foundation of China (No. 21203152).

\section{References}

1. Deng SD, Li XH (2012) Inhibition by Jasminum Nudiflorum Lindl. Leaves Extract of the Corrosion of Aluminium in $\mathrm{HCl}$ Solution. Corros Sci 64: 253-262.

2. Yurt A, Ulutas S, Dal H (2006) Electrochemical and Theoretical Investigation on the Corrosion of Aluminium in Acidic Solution Containing Some Schiff Bases. Appl Surf Sci 253: 919-925

3. Sherif E, Park S M (2006) Effects of 1,4-Naphthoquinone on Aluminum Corrosion in 0.50M Sodium Chloride Solutions. Electrochim Acta 51: 13131321.

4. Oguzie E (2007) Corrosion Inhibition of Aluminium in Acidic and Alkaline Media by Sansevieria Trifasciata Extract. Corros Sci 49: 1527-1539.

5. El-Etre AY (2001) Inhibition of Acid Corrosion of Aluminum Using Vanillin Corros Sci 43: 1031-1039.

6. Oguzie E, Okolue B, Ebenso E, Onuoha G, Onuchukwu Al (2004) Evaluation of the Inhibitory Effect of Methylene Blue Dye on the Corrosion of Aluminium in Hydrochloric Aci. Mater Chem Phys 87: 394-401.

7. Maayta A, Al-Rawashdeh N (2004) Inhibition of Acidic Corrosion of Pure Aluminum by Some Organic Compounds. Corros Sci 46: 1129-1140.

8. Khaled K (2010) Electrochemical Investigation and Modeling of Corrosion Inhibition of Aluminum in Molar Nitric Acid Using Some Sulphur-containing Amines. Corros Sci 52: 2905-2916.

9. Zhang Q, Hua $Y$ (2010) Corrosion Inhibition of Aluminum in Hydrochloric Acid Solution by Alkylimidazolium Ionic Liquids. Mater Chem Phys 119: 57-64.
10. Li WH, Zhao X, Liu FQ, Hou BR (2008) Investigation on Inhibition Behavior of S-triazole-triazole Derivatives in Acidic Solution. Corros Sci 50: 3261-3266.

11. Bekkouch K, Aouniti A, Hammouti B, Kertit S (1999) Corrosion Inhibition of a Carbon Steel in 2M H3PO4 Medium by "triazine" Compounds. J Chim Phys PCB 96: 838-850.

12. Yoo SH, Kim YW, Chung K, Kim NK, Kim JS (2013) Corrosion Inhibition Properties of Triazine Derivatives Containing Carboxylic Acid and Amine Groups in 1.0 M HCl Solution. Ind Eng Chem Res 52: 10880-10889.

13. Wang F, Liu JJ, Li YF, Fan RB, Li YN (2012) Complex Barrier Layer of Triazinedithoil Prepared by Electrodeposition and Initiated Polymerization on Aluminum Alloy towards Corrosion Protection. Int J of Electrochem Sci 7: 3672 3680 .

14. Wang F, Wang YB, Li YN, Wang Q (2010) Preparation of Triazine Thio Polymeric Nano-film by Electrochemical Polymerization on Aluminum Surface. J Mater Sci Eng 4: 524-528.

15. Ebenso EE (2003) Effect of Halide Ions on the Corrosion Inhibition of Mild Stee in H2SO4 Using Methyl Red-Part 1. B Electrochem 19: 209-216.

16. Ahamad I, Gupta C, Prasad R, Quraishi MA (2010) An Experimental and Theoretical Investigation of Adsorption Characteristics of a Schiff Base Compound as Corrosion Inhibitor at Mild Steel/hydrochloric Acid Interface. J Appl Electrochem 40: 2171-2183.

17. Ferreira ES, Giacomelli C, Giacomelli FC, Spinelli A (2004) Evaluation of the Inhibitor Effect of L-ascorbic Acid on the Corrosion of Mild Steel. Mater Chem Phys 83: 129-134

18. Safak S, Duran B, Yurt A, Turkoglu G (2012) Schiff bases as Corrosion Inhibitor for Aluminium in $\mathrm{HCl}$ Solution. Corros Sci 54: 251-259.

19. Fuchs-Godec R, Dolecek V (2004) A Effect of Sodium Dodecylsulfate on the Corrosion of Copper in Sulphuric Acid Media. Colloids and Surfaces A: Phys Eng Asp 244: 73-76.

20. Zhao TP, Mu GN (1999) The Adsorption and Corrosion Inhibition of Anion Surfactants on Aluminium Surface in Hydrochloric Acid. Corros Sci 41: 19371944.

21. Smialowska Z S, Mankowski J (1978) Crevice Corrosion of Stainless Steels in Sodium Chloride Solution. Corros Sci 18: 953-960.

22. Oguzie EE, Li Y, Wang FH (2007) Effect of Surface Nanocrystallization on Corrosion and Corrosion Inhibition of Low Carbon Steel: Synergistic Effect of Methionine and Iodide Ion. Electrochim Acta 52: 6988-6996. 